10.2003xicist

American Journal of Scientific Research and Essays

(ISSN:2475-7527)

\title{
Experimental study on scouring of coarse sand and fine sand seabed caused by propeller washing in front of solid wharf
}

\section{Shuo Zhang}

College of Ocean Science and Engineering, Shanghai Maritime University, Shanghai 201306, China

\section{ABSTRACT}

This paper presents the results of continuous scouring and intermittent scouring tests on two kinds of seabed soils (d50 $=0.7 \mathrm{~mm}$ coarse sand and $\mathrm{d} 50=0.162 \mathrm{~mm}$ fine sand) induced by propeller washing at the front of the solid wharf. Three propellers with diameters of $70 \mathrm{~mm}, 130 \mathrm{~mm}$ and $150 \mathrm{~mm}$ were used for the test. The test results show that under the same test conditions, the maximum scouring depth of the coarse sand seabed is $8.2 \%$ to $58 \%$ deeper than that of the fine sand seabed under continuous test or intermittent scouring; compared with continuous scouring, intermittent scouring The maximum scouring depth increase caused by the coarse sand seabed is $2 \%$ to $4.8 \%$, while it is increased to $5.1 \%$ to $37 \%$ for the fine sand seabed. The prediction formula of the maximum equilibrium scouring depth on the fine sand seabed caused by the front edge of the solid wharf during the intermittent washing of the propeller is established. This formula is a dimensionless formula, which can be applied to the intermittent scouring of the actual propeller wash.

\section{Keywords:}

propeller washing; continuous scouring; intermittent scouring; solid wharf; coarse sand; fine sand
*Correspondence to Author:

Shuo Zhang

College of Ocean Science and Engineering, Shanghai Maritime University, Shanghai 201306, China

How to cite this article:

Shuo Zhang. Experimental study on scouring of coarse sand and fine sand seabed caused by propeller washing in front of solid wharf. American Journal of Scientific Research and Essays, 2018 3:14.

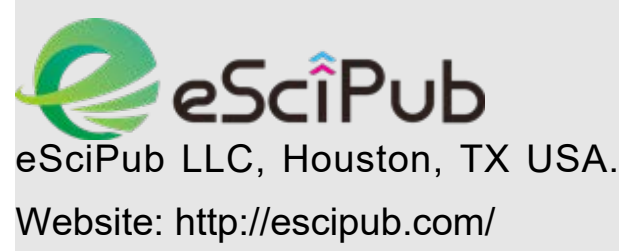




\section{Introduction}

With the use of high-power engines on ships and the improvement of maneuverability of ships, the scouring of propeller washes in front of physical docks is becoming an important part of scouring research because it directly affects the water quality environment of inland or shallow seas. Stability of the structural basis ${ }^{[1]}$. Previous studies have focused on the effects of propeller position, wash flow field, and physical dock position on the flushing of the propeller wash stream. However, the actual scouring situation is that, considering the randomness of the ship's mooring or anchoring, the flushing of the propeller wash stream cannot be completed continuously in one time, but is intermittently or discontinuously gradually reaching a balanced flushing state.

Hamill (1999) ${ }^{[2]}$ carried out the scrub test of the seabed of the sand by the propeller wash at the quay dock. The test used four propeller models with different speeds, from the shore wall (the distance from the propeller to the maximum scour point when there is no structure) The prediction formula for the equilibrium scouring depth at the bottom of the bank is established by comparison with the scouring characteristics in the absence of structures (Hamill 1999 or Sumer and Fredsøe's 2002 $2^{[3-4]}$. Schokking ${ }^{[5]}(2002)$ utilizes simple water jets, respectively. The ducted propeller jet and the free propeller jet test study the stability of the soil on the slope. He found that the stability of the soil during the jet flow of the ducted propeller is greatly different from the stability of the soil under the simple water jet. Therefore, it is not possible to replace the propeller jet with a simple water jet in the experiment. ${ }^{[6]}(2005)$ studied the existence of the wall by the model test on the initial jet velocity and axial direction when the dock wall is 2 times and 3 times the propeller diameter respectively. Influence of flow rate attenuation, etc. Hamill[](2009) used model tests to study the effect of rudder on the water flow at the bottom of the seabed generated by the propeller. The method of using neural network to predict the flow velocity at the bottom of the seabed is proposed. Xie Zhikai ${ }^{[8]}(2004)$ conducted the erosion test of the foundation soil of the wharf caused by the propeller water when the container ship was docked and offshore. Teresa ${ }^{[9]}(2010)$ The effect of the rudder on the propeller wash flow field when the double-propeller is leaving the shore is studied by using a model scale of $1: 16$. It is found that the high-power ship can not ignore the tangential flow rate and radial direction generated by the propeller when operating in shallow water. The effect of the flow rate on the scouring. The above test methods are based on the continuous operation of the propeller, and do not consider the change of the scouring characteristics caused by the intermittent work of the propeller and the change of the characteristics of the soil particles. Therefore, it is necessary to carry out different soil particles. Intermittent scouring test study of propeller wash flow on the seabed.

In this paper, the continuous scouring test of propeller washing in nine kinds of seabed soils and the intermittent scouring test under 18 working conditions were carried out by physical model test. The characteristics of seabed soil and the interval of propeller were studied. The effect of sex work on balancing the depth of erosion. Finally, the prediction formula of the maximum intermittent scouring depth is established by using the experimental data.

\section{2. test}

The test was carried out in a water tank of 2.0 
$\mathrm{m}$ in length, $1.2 \mathrm{~m}$ in width and $1.2 \mathrm{~m}$ in height. instruments can be found in ${ }^{[10]}$.

The rotary motion of the propeller is generated by a motor with a power of $0.75 \mathrm{~kW}$. Simulate a solid wharf surface with transparent tempered glass. The scouring test phenomenon can be observed in front of the transparent tempered glass. The scour terrain of the front edge of the physical wharf is measured using a three-dimensional topographic surveyer. A detailed description of the test equipment and

\subsection{Propeller parameters}

In order to produce different propeller wash flow fields, three types of propellers were used in the test, and the diameters of the propellers were $70 \mathrm{~mm}, 130 \mathrm{~mm}$ and $150 \mathrm{~mm}$, respectively. The characteristics of the propeller are described in detail in Table 1. The plane position and height of the propeller in the water tank are the same as in the literature ${ }^{[10] .}$

\section{Table 1 Characteristic parameters of propeller to be used in experiment}

\begin{tabular}{cccccc}
\hline $\begin{array}{c}\text { Propell } \\
\text { er }\end{array}$ & $D_{p}(\mathrm{~mm})$ & $\begin{array}{c}\text { Number } \\
\text { blades }\end{array}$ & of & $V_{0}(\mathrm{~m} / \mathrm{s})$ & $\begin{array}{r}\text { Speed (rpm) } \\
\text { used } \\
\text { in the test }\end{array}$ \\
\hline 1 & 150 & 4 & 1.207 & 700 & $\operatorname{Re}_{j}$ \\
2 & 130 & 4 & 1.124 & 700 & $7.8 \times 10^{4}-1.7 \times 10^{5}$ \\
3 & 70 & 4 & 0.825 & 1680 & $4.2 \times 10^{4}-1.4 \times 10^{5}-8.5 \times 10^{4}$ \\
\hline
\end{tabular}

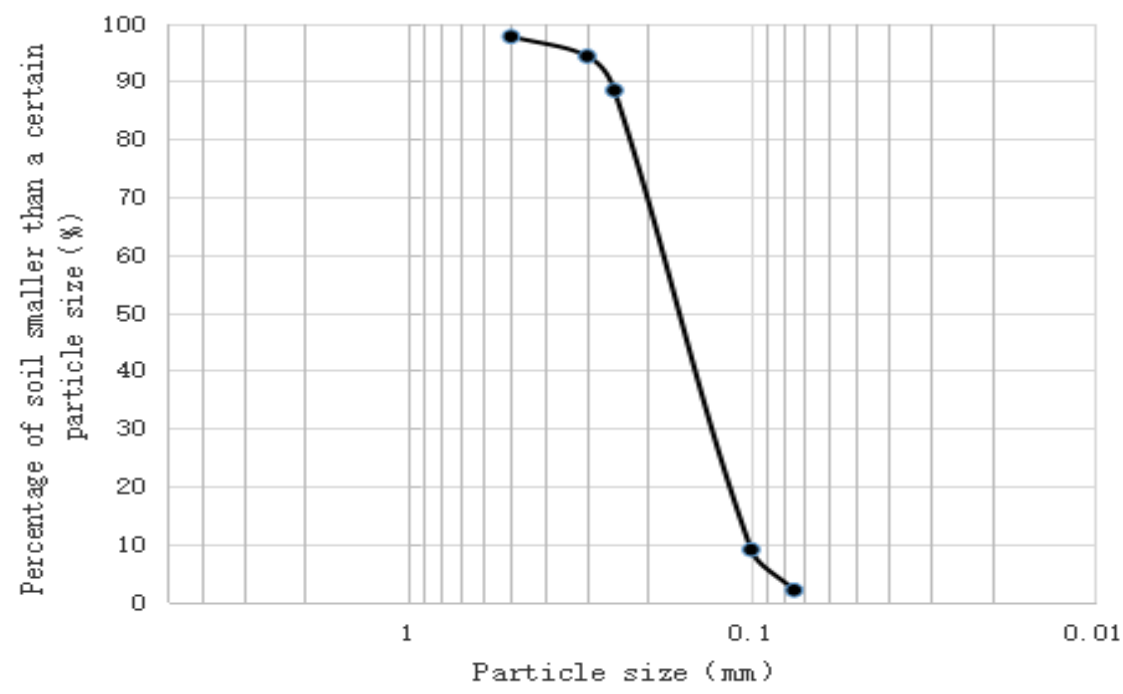

Fig.1 Analysis of soil size grading in experiment

\subsection{Soil samples}

Two soil samples were used in the test. One soil sample is coarse sand $(\mathrm{d} 50=0.7 \mathrm{~mm})$, and the other soil sample is fine sand. The nature of the first soil sample can be found in the literature[10]. The nature of another soil sample can be obtained from the parti-cle grading curve given in Figure 1. The median diameter 
of the soil sample ob-tained from the figure is that the particle content of the particle diameter greater than $0.075 \mathrm{~mm}$ is greater than $85 \%$ of the total weight.2.3 Scour test

The continuous flush test and the intermittent flush test of the propeller wash flow were carried out for the two soil samples. Table 2 gives a detailed description of the conditions of the flush test. The continuous scouring test of each soil sample was carried out in 9 cases, and the intermittent scouring test was carried out in 9 cases under the intermittent scouring time of 2 min and 3 min, respectively. Specific experimental procedures and procedures can be found in the literature ${ }^{[10]}$.

Table 2 Scour test conditions

\begin{tabular}{|c|c|c|c|c|c|c|c|c|}
\hline $\begin{array}{l}\text { Working } \\
\text { condition } \\
\text { parameter }\end{array}$ & $\begin{array}{c}\text { Propeller } \\
\text { diameter } \\
(\mathrm{mm})\end{array}$ & $\begin{array}{l}\text { Distance } \\
\text { to the pier } \\
\quad(\mathrm{mm})\end{array}$ & $\begin{array}{l}\text { Height } \\
\text { from the } \\
\text { seabed } \\
(\mathrm{mm})\end{array}$ & $\begin{array}{c}\text { Propelle } \\
\text { r wash } \\
\text { speed } \\
\text { (rpm) }\end{array}$ & $\begin{array}{l}V_{0}(\mathrm{~m} / \mathrm{s}) \\
\text { (Exit flow } \\
\text { rate) }\end{array}$ & $\begin{array}{l}\text { Continuous } \\
\text { flushing time } \\
\qquad(\mathrm{min})\end{array}$ & $\begin{array}{l}\text { Intermitten } \\
\text { t flushing } \\
\text { time (min) }\end{array}$ & $\begin{array}{c}\text { Intermitten } \\
\text { t flushing } \\
\text { total time } \\
\quad(\min )\end{array}$ \\
\hline $\begin{array}{l}\text { Working } \\
\text { condition1 }\end{array}$ & 150 & 500 & 300 & 700 & 1.04 & 6 & $2 / 3$ & 6 \\
\hline $\begin{array}{l}\text { Working } \\
\text { condition2 }\end{array}$ & 150 & 900 & 300 & 700 & 1.04 & 6 & $2 / 3$ & 6 \\
\hline $\begin{array}{l}\text { Working } \\
\text { condition3 }\end{array}$ & 150 & 1200 & 300 & 700 & 1.04 & 6 & $2 / 3$ & 6 \\
\hline $\begin{array}{l}\text { Working } \\
\text { condition4 }\end{array}$ & 130 & 500 & 300 & 700 & 0.90 & 6 & $2 / 3$ & 6 \\
\hline $\begin{array}{l}\text { Working } \\
\text { condition5 }\end{array}$ & 130 & 900 & 300 & 700 & 0.90 & 6 & $2 / 3$ & 6 \\
\hline $\begin{array}{l}\text { Working } \\
\text { condition6 }\end{array}$ & 130 & 1200 & 300 & 700 & 0.90 & 6 & $2 / 3$ & 6 \\
\hline $\begin{array}{l}\text { Working } \\
\text { condition7 }\end{array}$ & 70 & 500 & 300 & 1680 & 1.16 & 6 & $2 / 3$ & 6 \\
\hline $\begin{array}{l}\text { Working } \\
\text { condition8 }\end{array}$ & 70 & 900 & 300 & 1680 & 1.16 & 6 & $2 / 3$ & 6 \\
\hline $\begin{array}{l}\text { Working } \\
\text { condition9 }\end{array}$ & 70 & 1200 & 300 & 1680 & 1.16 & 6 & $2 / 3$ & 5 \\
\hline
\end{tabular}

\section{3. test results analysis}

3.1 Influence of soil characteristics of seabed on continuous scouring depth and intermittent scouring depth

The test results of the working conditions 7,8 , and 9 were taken from the nine working conditions to analyze the influence of the soil characteristics of the seabed on the continuous scouring depth. Figures 2(a)-2(c) show the equilibrium scouring depths in the plane of the propeller axis during continuous scouring, respectively, for conditions 7,8 , and 9 . In the 
figure, the dotted line and the thin solid line respectively indicate the equilibrium scouring depth caused by the propeller wash on the coarse sand seabed and the fine sand seabed under the same test conditions. It can be seen from the figure that under the same test conditions, no matter the seabed soil is fine sand or coarse sand, the farther the propeller is from the wharf surface, the smaller the maximum scour depth of the seabed; under the same test conditions, the coarse sand ratio The maximum scour depth of the fine sand seabed is $8.2 \%$ to $58 \%$, and the farther the propeller is from the wharf surface, the greater the increase of the maximum scour depth of the coarse sand than the fine sand seabed.

The test results of working conditions 2,5 , and 8 were taken from 9 working conditions to analyze the influence of the soil characteristics of the seabed on the intermittent scouring depth. Figures 3(a)-3(c) show the equilibrium scouring depths in the plane of the propeller axis when the conditions 2,5 , and 8 are intermittently flushed for $2 \mathrm{~min}$. In the figure, the dotted line and the thin solid line respectively indicate the equilibrium scouring depth caused by the propeller wash on the coarse sand seabed and the fine sand seabed under the same test conditions. It can be clearly seen from the figure that the intermittent scouring is strong or weak regardless of the washing flow field of the propeller, and the equilibrium scouring depth of the coarse sand seabed is larger than that of the fine sand seabed; the maximum scouring depth of the coarse sand seabed It is about $10 \%$ larger than the fine sand seabed.

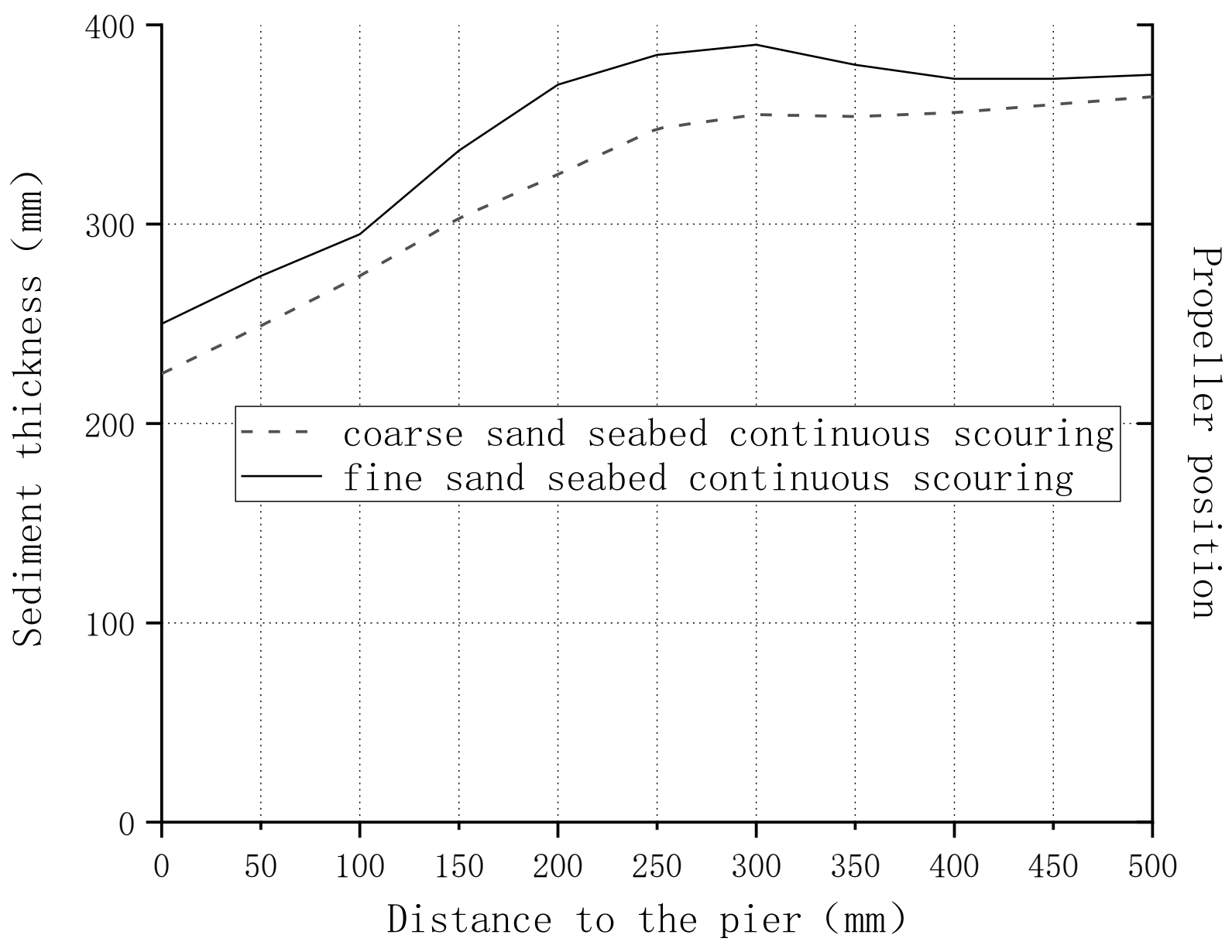

(a) 


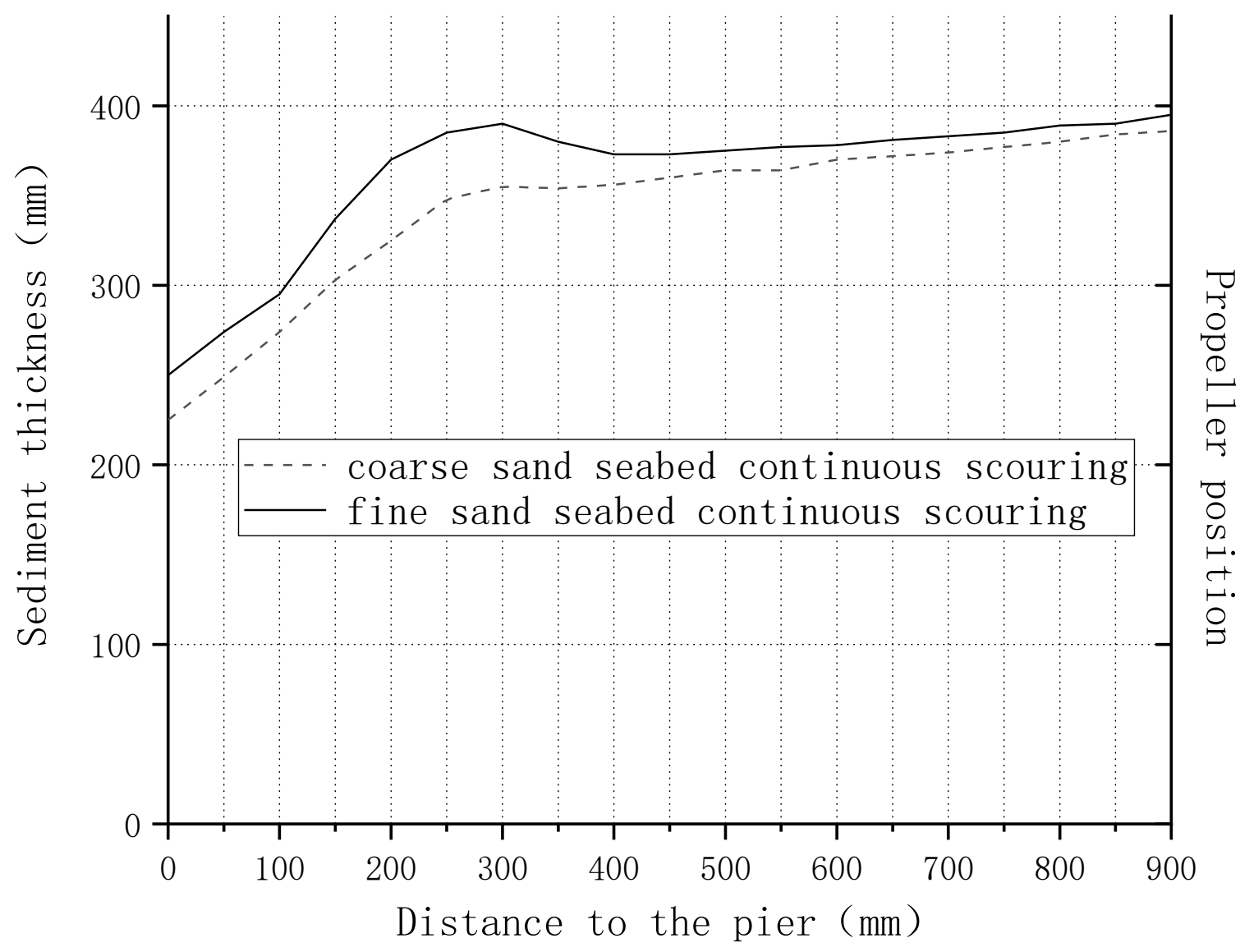

(b)

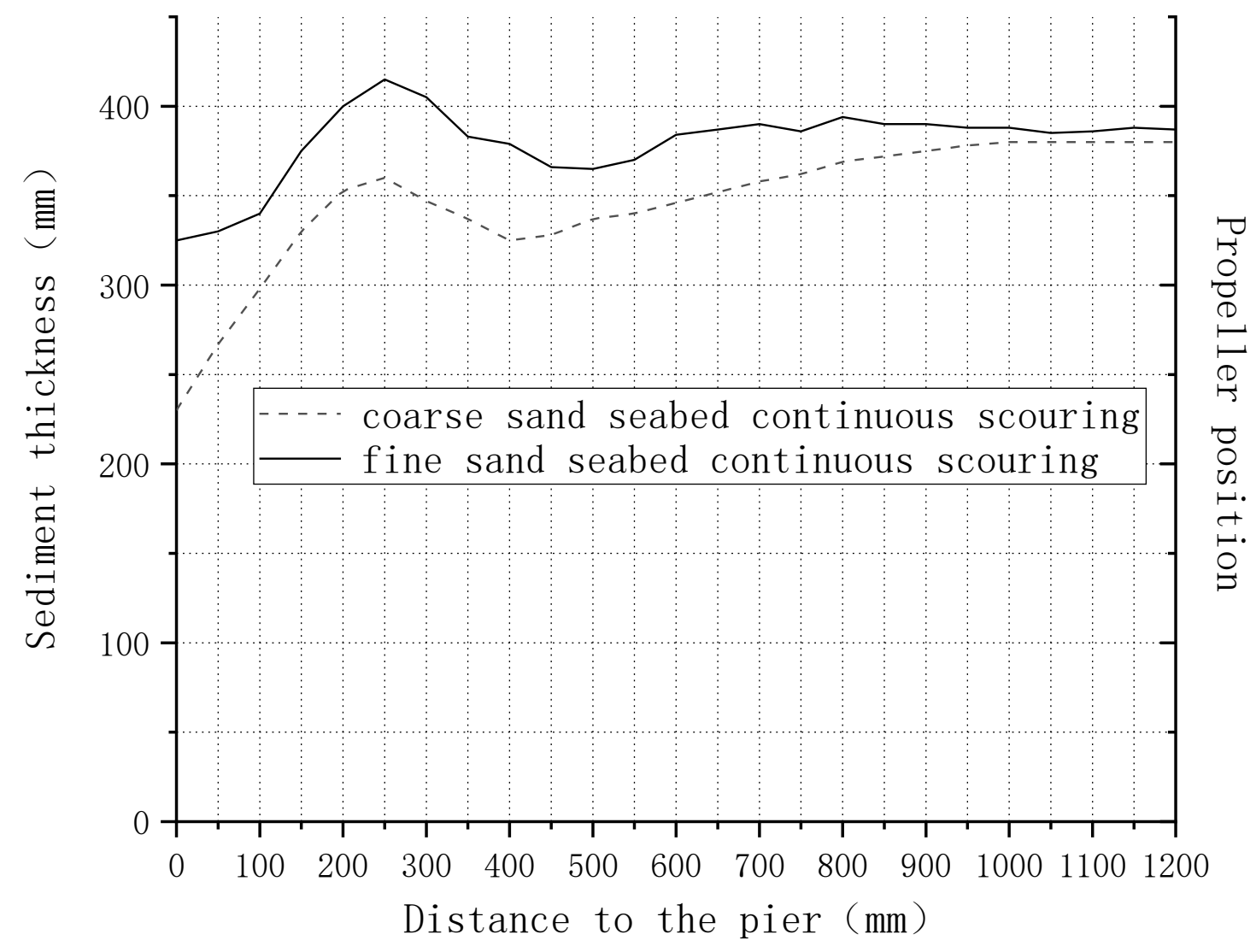

(c)

Fig.2 Equilibrium scour profiles at the centerline plane in continuous-scour case 


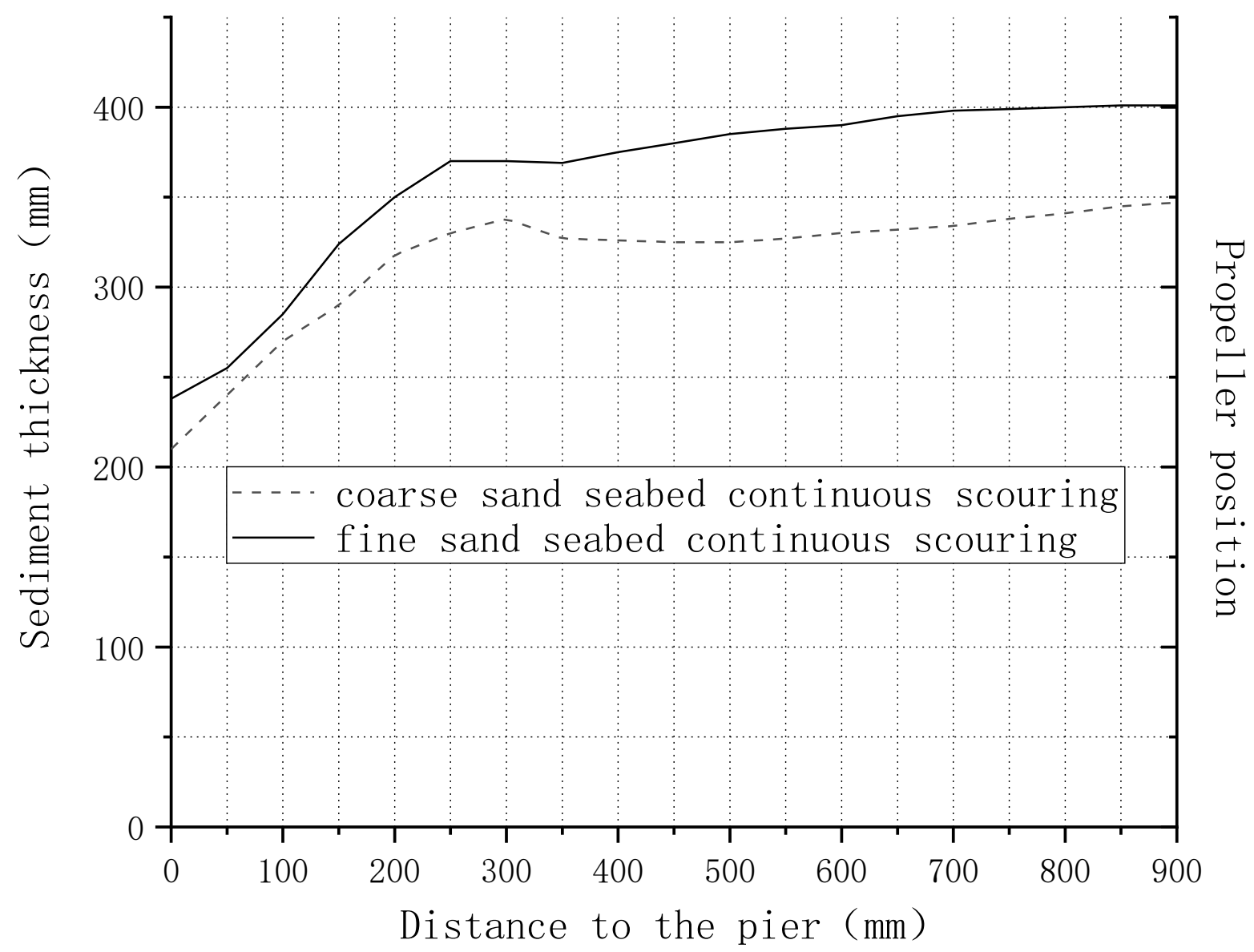

(a)

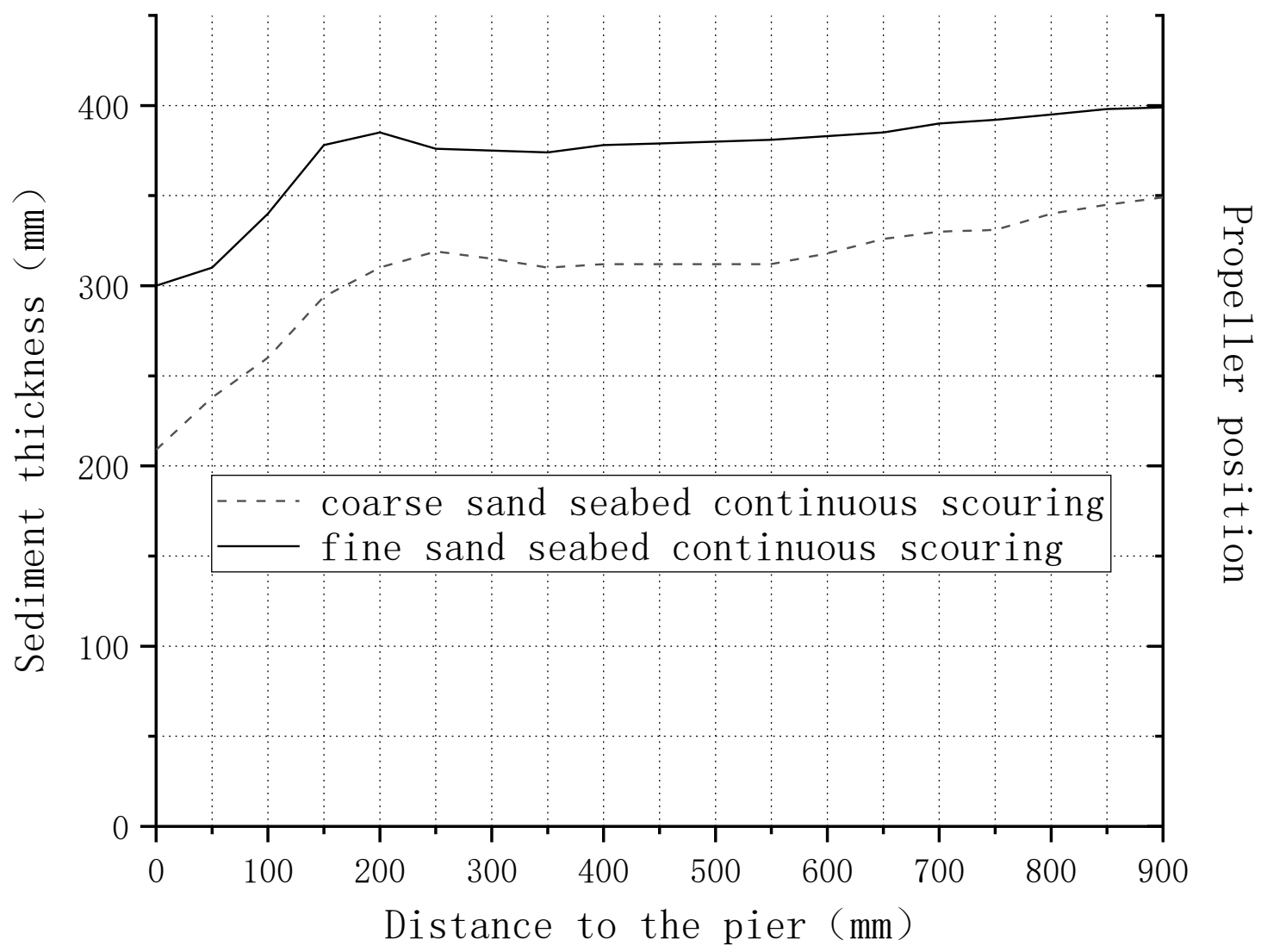

(b) 


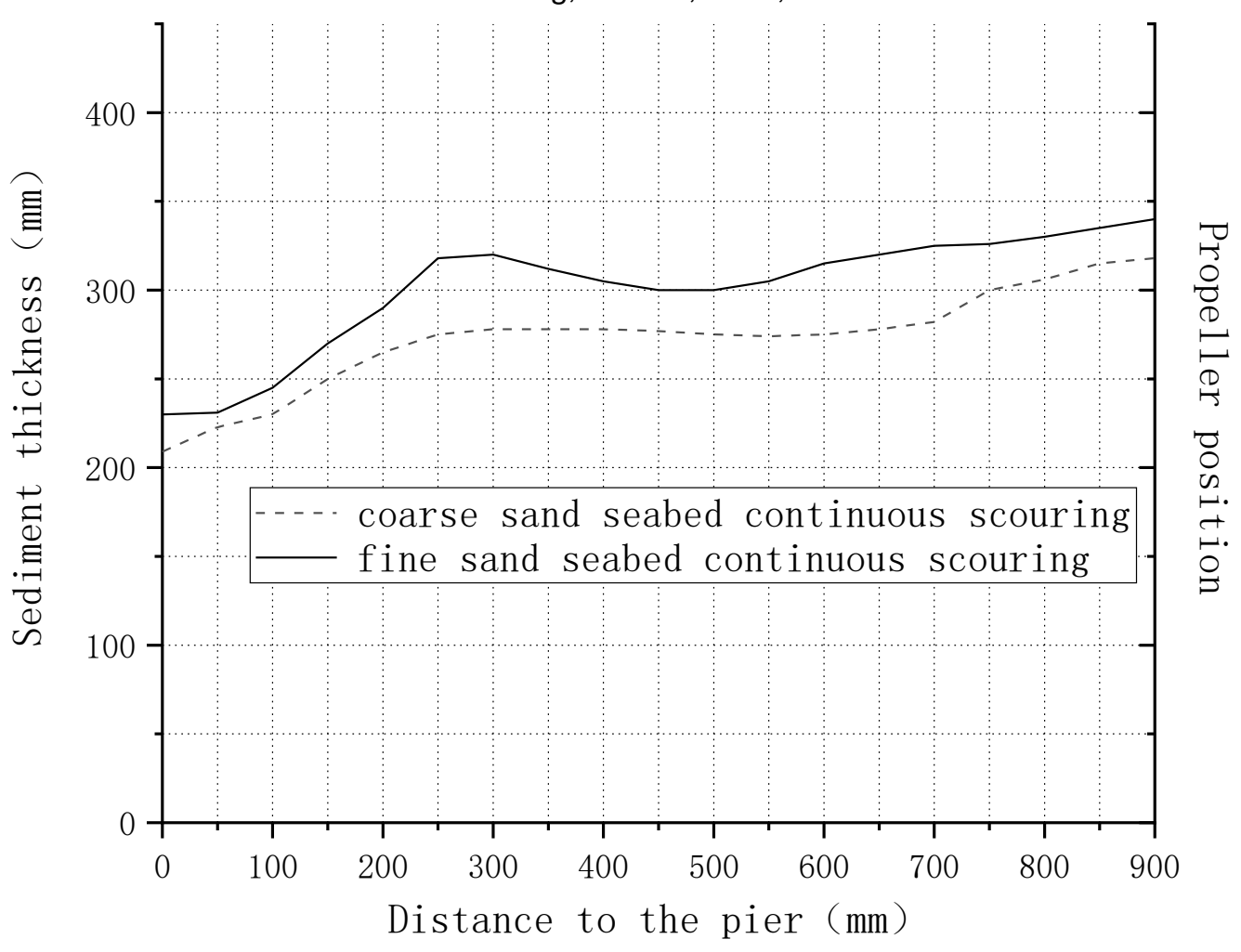

(c)

Fig.3 Equilibrium scour profiles at the centerline plane in intermittent-scour case

\subsection{Effect of intermittent work of propeller} on maximum equilibrium scouring depth

In order to analyze the influence of the intermittent work of the propeller on the scouring depth, this paper takes out the working condition 2, the working condition 5 and the working condition 8 from 9 working conditions, that is, when the propeller is 900 $\mathrm{mm}$ from the wharf surface, the propeller diameter is $70 \mathrm{~mm}, 130 \mathrm{~mm}$ and At $150 \mathrm{~mm}$, the maximum scouring depth at different intermittent scouring times is compared.

Table 3 and Table 4 respectively show the maximum intermittent scouring depth values of the fine sand seabed and the coarse sand seabed under the same test conditions with intermittent scouring time of $2 \mathrm{~min}$ and $3 \mathrm{~min}$, respectively. It can be seen from the table that when the intermittent flushing time is shortened from $3 \mathrm{~min}$ to $2 \mathrm{~min}$, the number of flushing times is increased from 2 to 3 times, and the maximum intermittent flushing depth corresponding to the three working conditions under the same test conditions is deepened to varying degrees. From this it can be inferred that in the intermittent operation of the propeller, the number of intermittent operations will affect the maximum flushing depth of the front edge of the physical dock, and the increase in the number of intermittent operations will increase the severity of the flushing.

Table 5 shows the ratio of the maximum scouring depth to the increase in continuous scouring at 2 min and 3 min on the coarse sand seabed and the fine sand seabed under the above three conditions. It can be seen from the table that the amount of increase caused by intermittent scouring on the coarse sand seabed is $5.1 \%$ to $37 \%$, and the increase caused by the fine sand seabed is only $2 \%$ to $4.8 \%$. It can be seen that the intermittent work AJSRE: http://escipub.com/american-journal-of-scientific-research-and-essays/ 
of the propeller has a greater influence on the sand seabed.

erosion of the fine sand seabed than the coarse

Table 3 The maximum scour depth in fine sand in intermittent-scour case under different conditions $(\mathrm{mm})$

\begin{tabular}{cccc}
\hline Working condition & 2 & 5 & 8 \\
\hline Intermittent flushing $(2 \min )$ & 268.2 & 198.1 & 260.4 \\
Intermittent flushing $(3 \min )$ & 263.7 & 195.6 & 257.1 \\
Deepen percentage & $1.7 \%$ & $1.2 \%$ & $1.3 \%$ \\
\hline
\end{tabular}

Table 4 The maximum scour depth in coarse sand in intermittent-scour case under different conditions $(\mathrm{mm})$

\begin{tabular}{cccc}
\hline Working condition & 2 & 5 & 8 \\
\hline Coarse sand seabed & 4.8 & 3 & 2 \\
Fine sand seabed & 37 & 13 & 5.1 \\
\hline
\end{tabular}

Table 5 Incremental ratio of the maximum scour depth in intermittent-scour case and that in continuous-scour case in different soil (\%)

\begin{tabular}{lccc}
\hline \multicolumn{1}{c}{ Working condition } & 2 & 5 & 8 \\
\hline Intermittent flushing $(2 \mathrm{~min})$ & 289.1 & 287 & 291.8 \\
Intermittent flushing (3min) & 284.7 & 282.3 & 284.8 \\
Deepen percentage & $1.5 \%$ & $1.6 \%$ & $1.3 \%$ \\
\hline
\end{tabular}

4.Prediction method of intermittent scouring depth

The prediction method of the maximum equilibrium scouring depth during continuous scouring is given in ${ }^{[2]}$. This method is also applicable to the continuous scouring situation in this paper. Reference ${ }^{[10]}$ gives a prediction method for the intermittent scouring depth on the coarse sand seabed, but this method only considers one type of propeller in the process of obtaining, which makes the prediction method have certain limitations. In order to expand the applicability of the intermittent scouring depth prediction method, this paper uses the intermittent scouring test results on the fine sand seabed to fit. When processing the test data, the maximum equilibrium scouring depth during intermittent scouring and the horizontal distance from the propeller to the wharf surface are dimensionlessly processed, and then the experimental data is fitted. On this basis, the maximum equilibrium depth during intermittent 
scouring is obtained. method of prediction.

The maximum equilibrium scouring depth $(\varepsilon \mathrm{mi})$ caused by intermittent flushing of the propeller on the fine sand seabed is inferior to the maximum equilibrium scouring depth $(\varepsilon \mathrm{mc})$ caused by continuous scouring, and then the difference and the maximum equilibrium scouring depth relative to the propeller shaft caused by continuous scouring (Ema) The producer gets $\left(\varepsilon \mathrm{mi}-\varepsilon_{\mathrm{mc}} / \varepsilon_{\mathrm{ma}}\right)$, which makes the maximum equilibrium scouring depth during intermittent scouring non-dimensional.The number of intermittent flushing is indicated by $n$, the continuous flushing time is represented by $\mathrm{T}$, the distance from the propeller to the wharf surface is represented by $\mathrm{Xw}$, and the $\mathrm{n} \mathrm{V}_{0} \mathrm{~T}$ and $X_{w}$ are obtained as a result to make the distance from the propeller to the wharf surface dimensionless. Then the horizontal distance from the dimensionless propeller to the wharf surface is the $x$ coordinate, the dimensionless maximum equilibrium scouring depth is the $y$ coordinate, and the experimental data is substituted into the set expressions of $x$ and $y$, thus obtaining the figure of Figure 4. Test data points shown (indicated by small squares in the figure). It can be seen from the experimental data points in the figure that the value of $Y$ appears in a monotonically decreasing state of the exponential form with the positive direction of $\mathrm{X}$, so the experimental data points can be fitted by an exponential function. After setting the exponential function relation, the prediction formula of the maximum equilibrium scouring depth during intermittent scouring is obtained by repeated fitting of the experimental data:

$$
\frac{\varepsilon_{m i}-\varepsilon_{m c}}{\varepsilon_{m a}}=0.17 \cdot\left(1+\frac{n V_{0} T}{X_{W}}\right)^{-2.85}
$$

In the formula, it indicates the maximum equilibrium flushing depth caused by intermittent flushing; it indicates the maximum equilibrium flushing depth caused by continuous flushing; it indicates the maximum equilibrium flushing depth with respect to the propeller shaft caused by continuous flushing; $\mathrm{n}$ indicates the number of intermittent flushing; indicating the propeller outlet flow velocity; Indicates the continuous scouring time; indicates the distance from the propeller to the wharf; indicates the maximum equilibrium scouring depth caused by continuous scouring, which can be calculated by the formula in ${ }^{[2]}$.

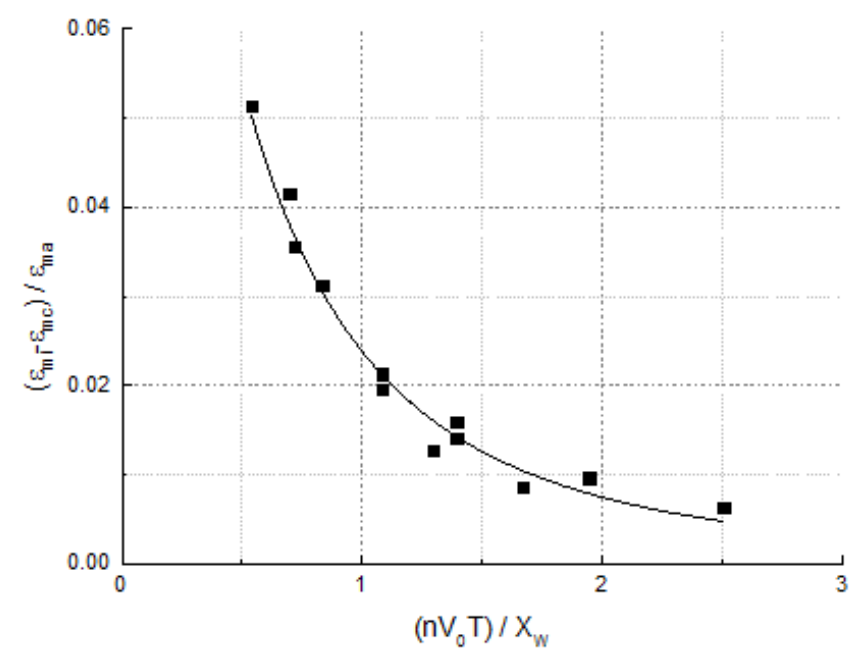

Figure 4 Intermittent and continuous scouring curves at different coordinates 


\section{Conclusion}

In this paper, the following conclusions can be drawn from the continuous scouring and intermittent flushing test of the coarse sand soil bed and the fine sand seabed on the front of the solid wharf by propeller washing:

1. Under the same test conditions, whether it is continuous scouring or intermittent scouring, the maximum scouring depth of the coarse sand seabed is larger than that of the fine sand seabed; and the farther the propeller is from the dock surface, the coarse sand is smaller than the fine sand sea. The greater the maximum increase in the depth of the bed.

2. When the propeller is working intermittently, the number of intermittent work will affect the maximum scouring depth of the front edge of the physical wharf. The increase of intermittent work times will aggravate the scouring phenomenon of the seabed.

3. Under the same test conditions, compared with continuous scouring, the maximum equilibrium scouring depth caused by intermittent scouring on the fine sand seabed is $5.1 \%$ to $37 \%$, while the increase on the coarse sand seabed is $2 \%$. To $4.8 \%$. It can be seen that the effect of intermittent scouring on the fine sand seabed is greater than that of the coarse sand seabed. Therefore, for fine sand, it is more necessary to consider the impact of the intermittent work of the propeller on the flushing.

4. The formula for predicting the maximum equilibrium scouring depth on the fine sand seabed caused by the front edge of the solid wharf during the intermittent washing of the propeller wash is established. This formula is a dimensionless formula that can be generalized to the case of actual propeller wash intermittent flushing.

\section{References}

1. Zheng Tianli. Hazards of Ship Propeller and Booster to Harbor Hydraulic Structures and Engineering Measures[J].Marine Transport Engineering, 2001,330 (7): $29 \sim 32$.

2. Hamill G. A., Johnston H.T. andStewart D.P. Propeller wash scour nearquay walls[J]. J.Waterway, Port, Coastal, and Ocean Engineering, ASCE, 1999,25(4):170 175.

3. Sumer B.M. and Fredsøe J. The Mechanicsof Scour in the Marine Environment[M]. WorldScientific Publisher, ISBN: 9810249306, 552 pages, 2002.

4. Sumer B.M.,Hatipoglu F. and Fredsøe J. Wave scour around a pile in sand, medium dense, anddense silt[J].Journal of waterway, port, coastal and ocean engineering, 2007, 133 (1): 14 27.

5. Laurens Schokking.Bowthruster-induced Damage[D].Master of Science thesis,Delft University of Technology, 2002.

6. Zang Xiaoyi, Xie Zhikai et al.Experiment discussion on the effect of quay-wall distance on the propeller water flow of ships [C]. Proceedings of the 27th Marine Engineering Symposium,2005.

7. Hamill G.A, Ryan D. and Johnston H.T. Effect of rudder angle on propeller wash velocities ata seabed[J]. Maritime Engineering, 2009, 162: 27 38.

8. XIE Zhi-kai. Experimental study on the effect of the quay-wall distance on the scouring of the bed caused by the propeller flow in the ship [D]. National Taiwan Ocean University, Hohai Engineering, Master's degree thesis, 2004.7.

9. Teresa Abramowicz-Gerigk. Distribution of flow velocity generated by propellers of twin propeller vessel[J].Scientific Journals,2010, 20(92): 5 12.

10. Shi Yu, Li Junhua, Liu Wenbai, Han Dingjun.Experimental Study of Intermittent Scouring of PropellerWasher Flow on Sandy Sea Bed Front of SolidWharf [J]. Waterway Harbor,2017, 38(5):458-463. 